\title{
Erratum to: Abstracts of the MASCC/ISOO 2015 Annual Meeting
}

The Publisher ${ }^{1}$

Published online: 1 August 2015

(C) Springer-Verlag Berlin Heidelberg 2015

Erratum to: Support Care Cancer (2015)

23 (Suppl 1):S1-S388

DOI 10.1007/s00520-015-2712-y

In the published Abstracts, the article title is incorrect in the $\mathrm{html}$ version. It should be: Abstracts of the MASCC/ISOO 2015 Annual Meeting 10.1007/s00520-015-2712-y.

The Publisher

1 Springer-Verlag Berlin,

Heidelberg, Germany 